\title{
Static and Dynamic Characterization of High-Speed Silicon Carbide (SiC) Power Transistors
}

\author{
Johnson A. Asumadu ${ }^{1}$, James D. Scofield ${ }^{2}$ \\ ${ }^{1}$ Electrical and Computer Engineering Department, Western Michigan University, Kalamazoo, USA \\ ${ }^{2}$ Air Force Research Laboratory/Propulsion Directorate, Power Division, Wright-Patterson Air Force Base, \\ Dayton, USA \\ E-mail:johnson.asumadu@wmich.edu,james.scofield.1@us.af.mil \\ Received September 14, 2009; revised July 23, 2010; accepted July 24, 2010
}

\begin{abstract}
This paper describes the operating characteristics of NPN 4H-SiC (a polytype of silicon carbide) bipolar junction transistor (BJT) and 4H-SiC Darlington Pairs. A large amount of experimental data was collected. The wafer BJTs were able to block over the rated $600 \mathrm{~V}$ in the common-emitter configuration and the TO-220 BJTs were able to block over the $1200 \mathrm{~V}$ rated voltage. In the thermal analysis, it is found out that at higher temperatures the forward and reverse (blocking) characteristics were stable at $100^{\circ} \mathrm{C}$ and $200^{\circ} \mathrm{C}$. The transistors show positive temperature coefficients of forward voltage $(V \mathrm{f})$. In general the current gain $(\beta)$ characteristics obtained (with $V \mathrm{CE}=6 \mathrm{~V}$ ) were approximately as expected for the BJTs. The $\beta$ s were very low ( 2 to 5 for wafer BJTs, 5 to 20 for the wafer Darlington Pairs, and 5 to 30 for TO-220 BJTs). The large amount of experimental data collected confirms some of the superior properties of the Silicon carbide material when used to fabricate power semiconductor devices, namely high thermal conductivity and high temperature operability. The data presented here will establish the trends and the performance of silicon carbide devices. The silicon carbide BJT has fast switching and recovery characteristics. From the analysis, silicon carbide power devices will be smaller (about 20 times) than a similar silicon power device and with reduced power losses. Silicon carbide will also be very useful for device integration in high densities, as found in integrated chips for current handling capabilities, for applications in instrumentation and measurements. Presently, most of the research is on improving the basic silicon carbide material quality, power device optimization, and applications engineering using devices that have been developed to date.
\end{abstract}

Keywords: Silicon Carbide, Static Characteristics, Dynamic Characteristics

\section{Introduction}

Today's efforts to replace conventional mechanical, hydraulic, and pneumatic power transfer systems with electric drives and their power electronics converters have taken off at an increasingly rapid rate (e.g., automobile electric brakes, traction control and electronic stability-control systems, electronic power-assisted steering (EPAS), etc.). The high demand for small power devices for instrumentation and measurements is expected to stay that way for many years to come, thereby challenging technology and circuit design in an unprecedented fashion. Biological and biologically-inspired instruments (e.g., nano-technology probes, MEMS, and so on) as well as portable equipment (e.g., laptops, palm pilots, camera recorders, midi players, meters, and more) are a few examples driving new areas of research in instrumentation and measurements. If silicon carbide $(\mathrm{SiC})$ devices (power transistors, integrated chips (ICs), etc.) are developed and commercialized, they will replace silicon $(\mathrm{Si})$ devices, since $\mathrm{SiC}$ devices will offer improvements to system weight, volume, losses, efficiency, and temperature capability. These improvements are needed over the next few years to realize the full potential of more-electric system paradigms and reduced power consumption goals. Table 1 illustrates many of the benefits $\mathrm{SiC}$ has to offer. This paper is an expansion and continuation of our paper [1] on the characteristics of $\mathrm{SiC}$ bipolar transistors.

Silicon carbide material has been widely studied be- 
Table 1. Comparison of the electrical and material properties of $\mathrm{Si}$ and $\mathrm{SiC}$.

\begin{tabular}{lcc}
\hline Property & $\mathrm{Si}$ & $\mathrm{SiC}$ \\
\hline Bandgap $(\mathrm{eV})$ & 1.11 & 3.5 \\
Maximum Temperature $\left({ }^{\circ} \mathrm{C}\right)$ & 425 & $>900$ \\
Maximum Voltage $\left(10^{6} \mathrm{~V} / \mathrm{cm}\right)$ & 0.3 & 4 \\
Thermal Conductivity $\left(\mathrm{W} / \mathrm{cm}^{\circ} \mathrm{C}\right)$ at $300^{\circ} \mathrm{K}$ & 1.5 & 5 \\
Electron Mobility $\left(\mathrm{cm}^{2} / \mathrm{Vs}\right)$ & 1350 & 500 \\
Dielectric Constant & 11.8 & 9.66 \\
Process Maturity & High & Low \\
Intrinsically Hard & NO & YES \\
\hline
\end{tabular}

cause it is a promising material for higher power and high temperature applications. The properties of $\mathrm{SiC}$ include high field electric breakdown $(2.2 \mathrm{MV} / \mathrm{cm})$, high saturated electron drift velocity $(2 \mathrm{E} 7 \mathrm{~cm} / \mathrm{s})$, and high thermal conductivity $(4.5 \mathrm{~W} / \mathrm{cm}-\mathrm{K})$ making $\mathrm{SiC}$ very attractive for high-voltage, high-frequency, high power semiconductor devices and switches, including those for instrumentation and measurement. The properties of $\mathrm{SiC}$ material and power devices have been documented over the last twenty years [2-6].

Although $6 \mathrm{H}-$ and $4 \mathrm{H}-\mathrm{SiC}$ polytypes are the most researched crystal structures, the $4 \mathrm{H}-\mathrm{SiC}$ polytype dominates power device development activity because the electron mobility in $4 \mathrm{H}-\mathrm{SiC}$ is two times that of $6 \mathrm{H}-\mathrm{SiC}$ perpendicular to the $c$-axis and about ten times that of $6 \mathrm{H}-\mathrm{SiC}$ parallel to the $c$-axis $[7,8]$. SiC Schottky Barrier Diodes (SBDs) have been available commercially since 2001 with 300 to 1200 volt, $175^{\circ} \mathrm{C}$ ratings. Although $\mathrm{SiC}$ power MOSFETs $[8,9]$ have received significant emphasis, they continue to suffer from poor MOS channel mobility and reliability, especially in the $4 \mathrm{H}-\mathrm{SiC}$ polytype. However, high voltage npn bipolar junction transistors (BJTs) and gate turn-off bipolar transistors (GTOs) in $4 \mathrm{H}-\mathrm{SiC}$ have been demonstrated $[9,12]$ with superior characteristics. SiC BJTs have been reported in the literature to block $1.8-2.5 \mathrm{kV}$ with peak currents of over 30 A, with DC current gains of 40 when operated in the common-emitter configuration. The active area of these devices was in the $1 \mathrm{~mm} \times 1.4 \mathrm{~mm}$ to $3.16 \mathrm{~mm} \times 3.16$ $\mathrm{mm}$ range. Static and dynamic characteristics of $6 \mathrm{H}-\mathrm{SiC}$ Diodes, BJTs, and MOSFETs have been presented [10], but have had drawbacks in performance because of the poor electron mobility in the vertical direction. Despite the superior theoretical properties of $\mathrm{SiC}$, material cost, base material quality, and substrate size are areas all requiring continued development and improvement prior to widespread technology adoption.

In this paper, the results of forward and reverse V-I characteristics, current gain characteristics, and dynamic measurements on $4 \mathrm{H}-\mathrm{SiC}$ Darlington Pairs and BJTs in the common-emitter configuration are presented. The BJTs were characterized in two formats - on wafer probing and in TO-220 packages. The Darlington Pairs were in the wafer die format only. The current and voltage ratings of the wafer power devices are $5 \mathrm{~A}$ and $600 \mathrm{~V}$, respectively, while the ratings of the TO-220 BJTs are 5 $\mathrm{A}$ and $1200 \mathrm{~V}$, respectively. The active area of the $4 \mathrm{H}-$ $\mathrm{SiC}$ Darlington Pairs and BJTs are in the range of 1 to 3 $\mathrm{mm}^{2}$ with emitter finger widths and spacings from $10 \mu \mathrm{m}$ $\times 15 \mu \mathrm{m}($ pitch $=25 \mu \mathrm{m})$ to $10 \mu \mathrm{m} \times 27 \mu \mathrm{m}($ pitch $=37$ $\mu \mathrm{m})$, respectively. Device data presented in this paper represent the measured performance characteristics observed from numerous devices of each type, enabling reasonable statistical inferences.

\section{Device Structure, Design, and Fabrication}

\subsection{Device Structure}

The BJTs came in two formats - on wafers and in TO220 packages. The Darlington Pairs were available only on wafers. The current and voltage ratings of the wafer power devices are $5 \mathrm{~A}$ and $600 \mathrm{~V}$, respectively, while the TO-220 BJTs are $5 \mathrm{~A}$ and $1200 \mathrm{~V}$. The Figure 1 shows a typical BJT cross-sectional diagram of the implanted device on a wafer. The maximum overall cross-sectional dimension of a typical transistor is $235 \mu \mathrm{m} \times 235 \mu \mathrm{m}$.

The substrate material used for both Darlington Pairs and BJTs was n-type, $20 \mathrm{~m} \Omega$-cm $4 \mathrm{H}-\mathrm{SiC}$ from Cree, Inc. on which n-collector, p-base, and n-emitter epitaxy of 10 $\mu \mathrm{m} 5 \mathrm{E} 15 \mathrm{~cm}^{-3}, 1 \mu \mathrm{m} 2 \mathrm{E} 17 \mathrm{~cm}^{-3}$, and $0.5 \mu \mathrm{m} 5 \mathrm{E} 19 \mathrm{~cm}^{-3}$, respectively, were grown. Devices with active areas in the range of 1 to $3 \mathrm{~mm}^{2}$ with emitter finger widths and spacings from $10 \mu \mathrm{m} \times 15 \mu \mathrm{m}$ (pitch $=25 \mu \mathrm{m})$ to $10 \mu \mathrm{m}$ $\times 27 \mu \mathrm{m}$ (pitch $=37 \mu \mathrm{m})$, respectively, were subsequently fabricated for testing. Figure 2 shows how a Darlington Pair and BJT images are laid out on a single wafer probing Reticle. There are several images on a

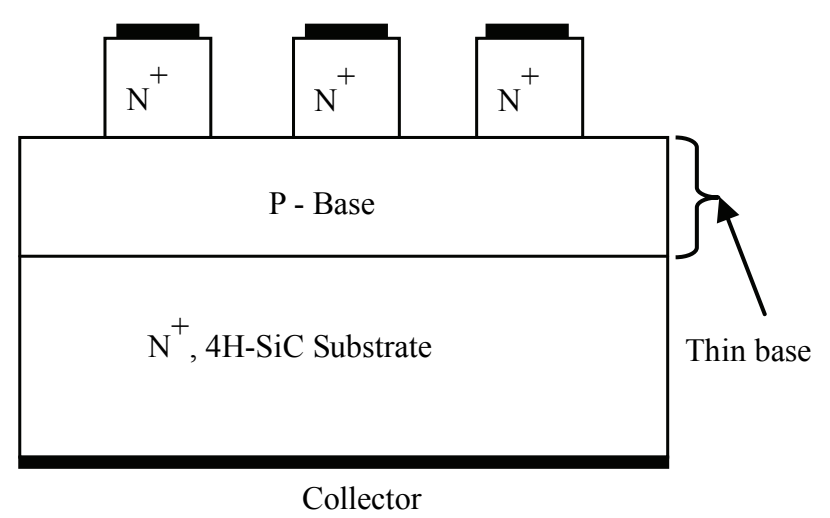

Figure 1. Simplified cross-section structure of $4 \mathrm{H}-\mathrm{SiC}$ BJT. 


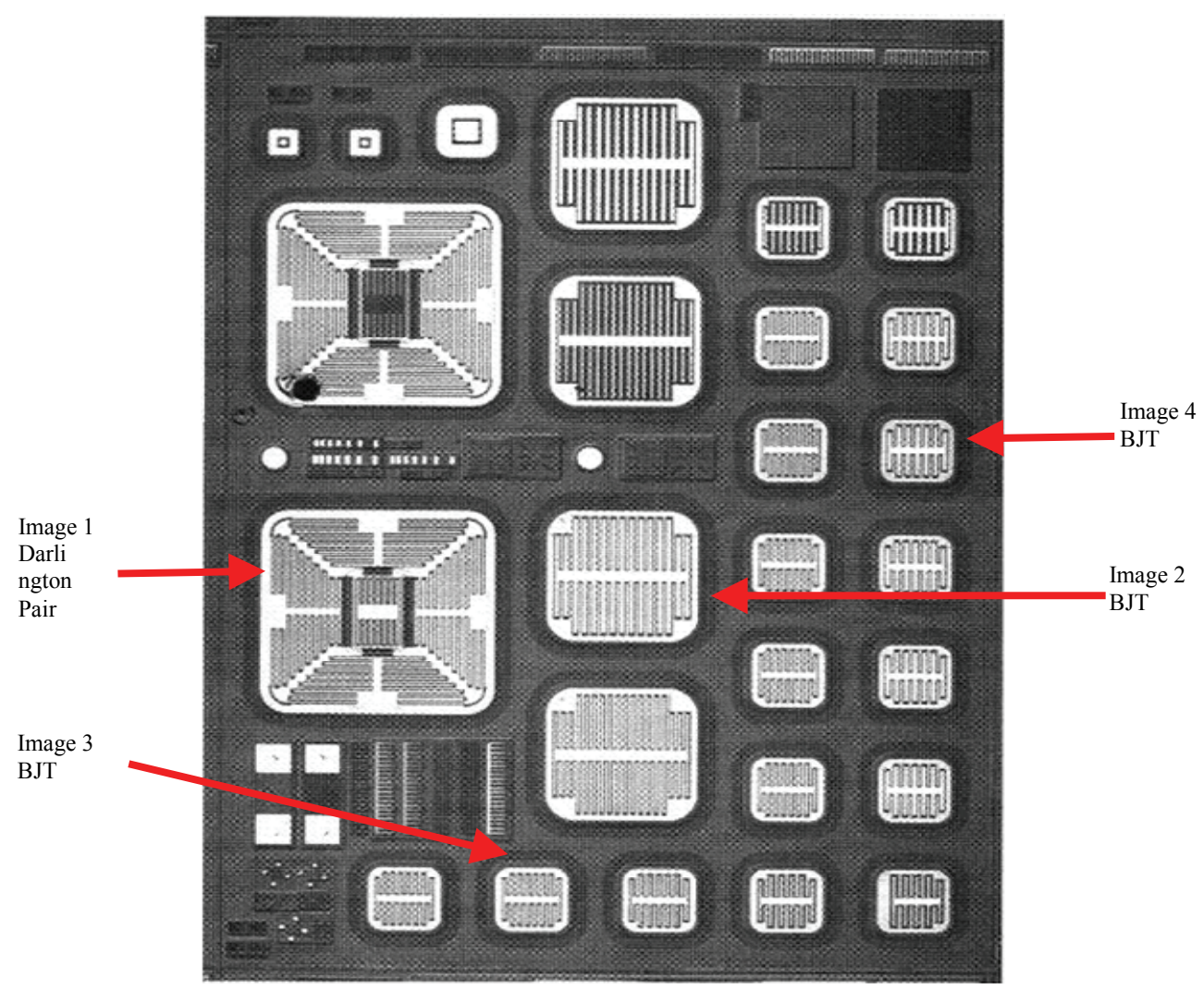

Figure 2. Reticle design layout of BJT and Darlington pair images.

Reticle. Image 1 on all the Reticles is a Darlington Pair and the remaining images are all BJTs. The characteristics were measured on 4 wafer Reticles with different orientation, resistivity, and thickness. The images selected on a Reticle are Image 1 - Darlington Pair and Images 2 to 4 - BJTs as shown in Figure 2.

\subsection{Device Design and Fabrication}

Table 2 shows the emitter configurations (emitter width $(x)$, base width $(y))$ and pitch $(x+y)$ of the selected Images 2, 3, and 4. The emitter configuration of Darlington Pair (Image 1) was not available (N/A). A Darlington Pair was designed to contain 54 emitter fingers and a BJT has 28 emitter figures. The distance between the implanted edge termination regions for devices is typically $2 \mu \mathrm{m}$. Table 3 shows the off-axis orientation, resistivity, and thickness of the four device wafer Reticles. Figure 3 shows examples of the top view of a fabricated 4H-SiC Darlington Pair and a BJT.

\section{Experimental Setup}

The forward and reverse $V$ ce vs. Ic characteristics were measured using Tektronix 371 curve tracer for both the wafer and the TO-220 BJTs. The dynamic characteristics were similarly measured but only on the TO-220 BJTs. Even though large amount of data was collected for these studies, results are presented for typical Darlington Pair and typical BJT devices from the wafer Reticles, and the TO-220 BJTs.

\section{Experimental Results and Discussions}

\subsection{Experimental Results - Wafer Probing 4H-SiC Darlington Pair and BJT}

\subsubsection{Forward and Reverse (Blocking) Characteristics}

The Figures 4 and 5 show the forward and reverse (blocking) Vce vs. Ic characteristics for a typical Dar-

Table 2. Reticle active area.

\begin{tabular}{cccc}
\hline Images & Emitter Width $(\mathrm{x})$ & Base Width $(\mathrm{y})$ & Pitch $(\mathrm{x}+\mathrm{y})$ \\
\hline 1 & N/A & N/A & N/A \\
2 & 15 & 15 & 30 \\
3 & 10 & 15 & 25 \\
4 & 15 & 15 & 30 \\
\hline
\end{tabular}




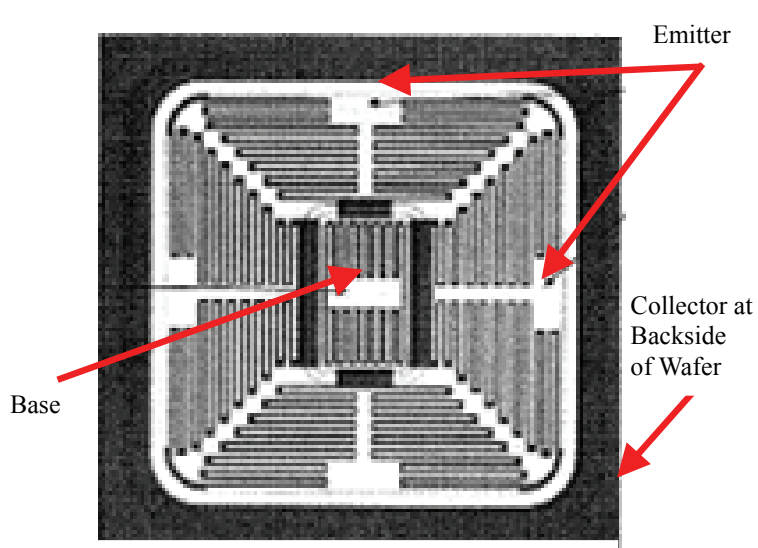

(a)

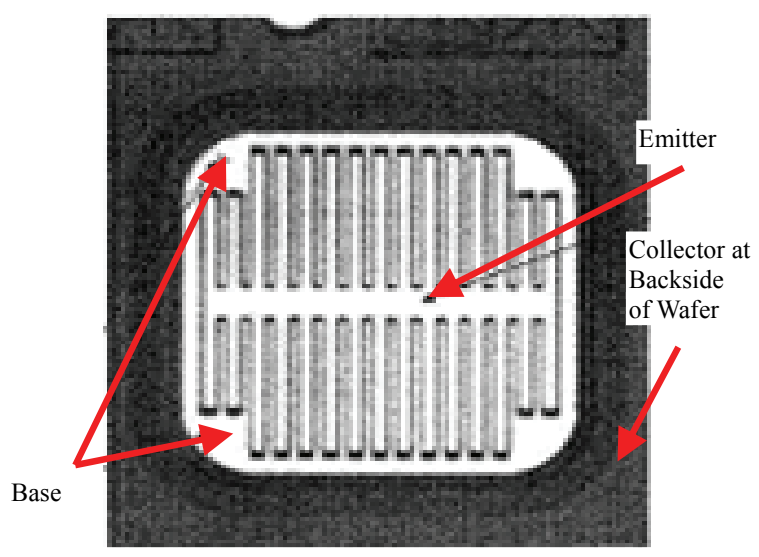

(b)

Figure 3. (a) Top view of a fabricated 4H-SiC Darlington Pair; (b) Top view of a fabricated $4 \mathrm{H}-\mathrm{SiC}$ BJT.

lington Pair (Image 1 on Reticle \# 2 ).

Similarly, the Figures 6 and $\mathbf{7}$ show the forward and reverse $V$ ce vs. Ic characteristics for a typical BJT (Image 4 on Reticle \#4). The sustaining voltage BVCE0 ranges from $200 \mathrm{~V}$ to $800 \mathrm{~V}$ for the Darlington Pair and from $200 \mathrm{~V}$ to $1200 \mathrm{~V}$ for the BJTs. The designed standoff voltage of the BJT epitaxy was $600 \mathrm{~V}$.

Reverse voltage characteristics depend on the drift layer thickness, the base doping used, and the base contact implantation tail, which tends to decrease the base width. High current gain and high reverse voltage can be achieved with the proper doping and width of base, and an optimized carrier lifetime.

\subsubsection{Current Gain}

The Figure 8 shows the forward current gain characteristics (base current $l \mathrm{~b}$ vs. $\beta$ ) of the above-mentioned devices. The maximum current gains $(\beta \max )$ occur at room temperature and decrease as temperature and base current increase. The low current gains in Darlington Pair and most of the BJT samples may be due to 1) low emit- ter injection efficiency because of high base doping and/ or low emitter doping, 2) low minority carrier life-times in the base layer, and 3) poor ohmic contact resistance of the $p+$ layer contact [9-12].

The Figure 8 also shows the effect of temperature on the common-emitter current gains $(\beta)$ from room temperature to $200^{\circ} \mathrm{C}$. As temperature increases, background carrier concentrations in the base region increase. This is due to an increase in the ionization fraction of the aluminum $\left(\mathrm{E}_{\mathrm{A}} \sim 200 \mathrm{meV}\right)$ acceptors, as a result, emitter
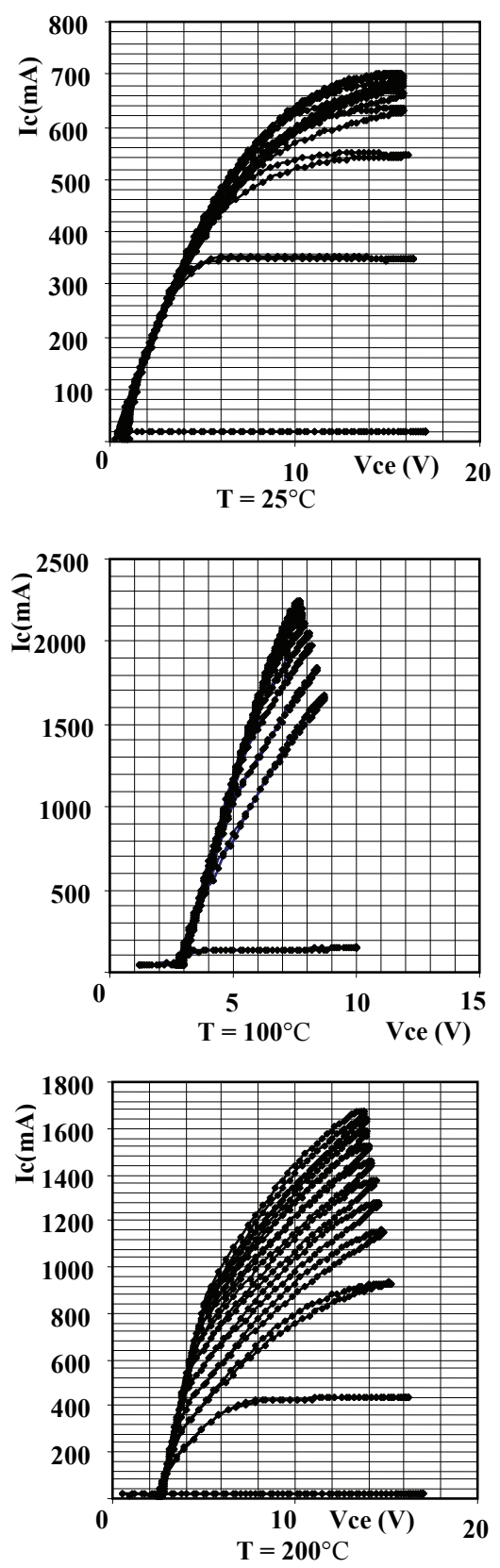

Figure 4. Darlington pair forward Vce-Ic characteristics at $25^{\circ} \mathrm{C}, 100^{\circ} \mathrm{C}, \& 200^{\circ} \mathrm{C}$. 

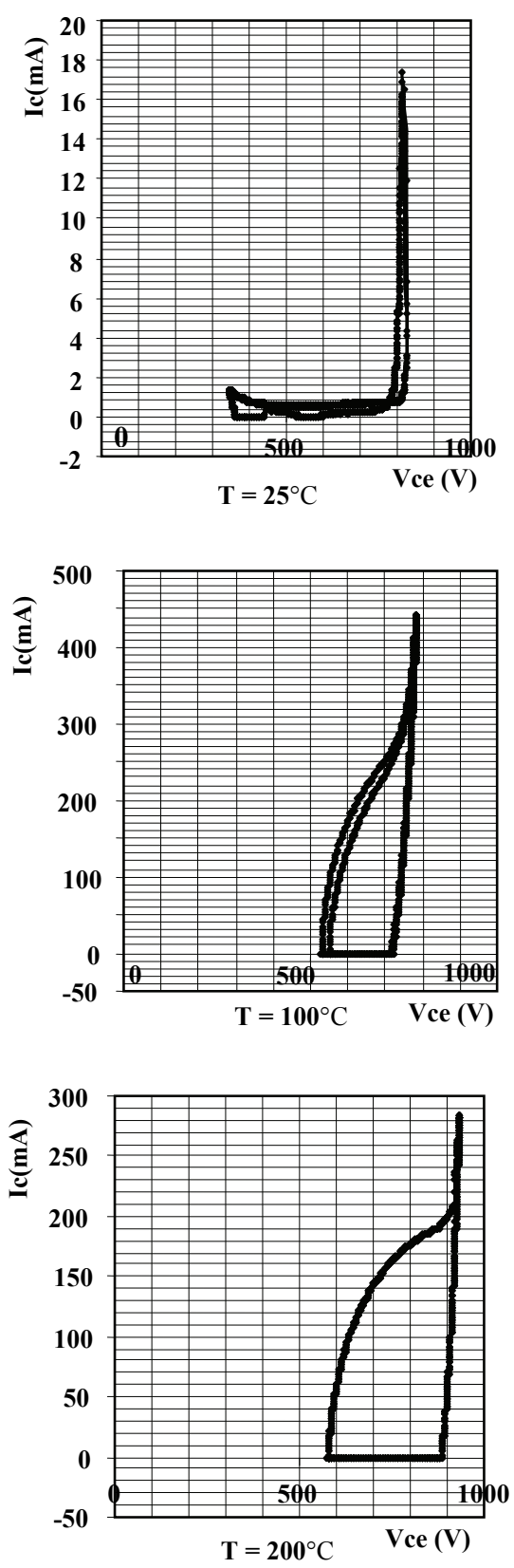

Figure 5. Darlington Pair reverse Vce-Ic characteristics at $25^{\circ} \mathrm{C}, 100^{\circ} \mathrm{C}, \& 200^{\circ} \mathrm{C}$.

injection efficiency decreases. As a consequence of this, increases with temperature to the minority carrier lifetimes are offset. The result is that the common-emitter current gain, $\beta$ decreases with temperature (a negative temperature coefficient not observed in silicon ( $\mathrm{Si}$ ) devices). This prevents thermal runaway and makes the $\mathrm{SiC}$ power device very attractive for paralleling. Also, the on-resistance will increase because of a decrease in collector layer electron mobility. In general, all the common-emitter current gain characteristics were in the range shown in Figure 8.
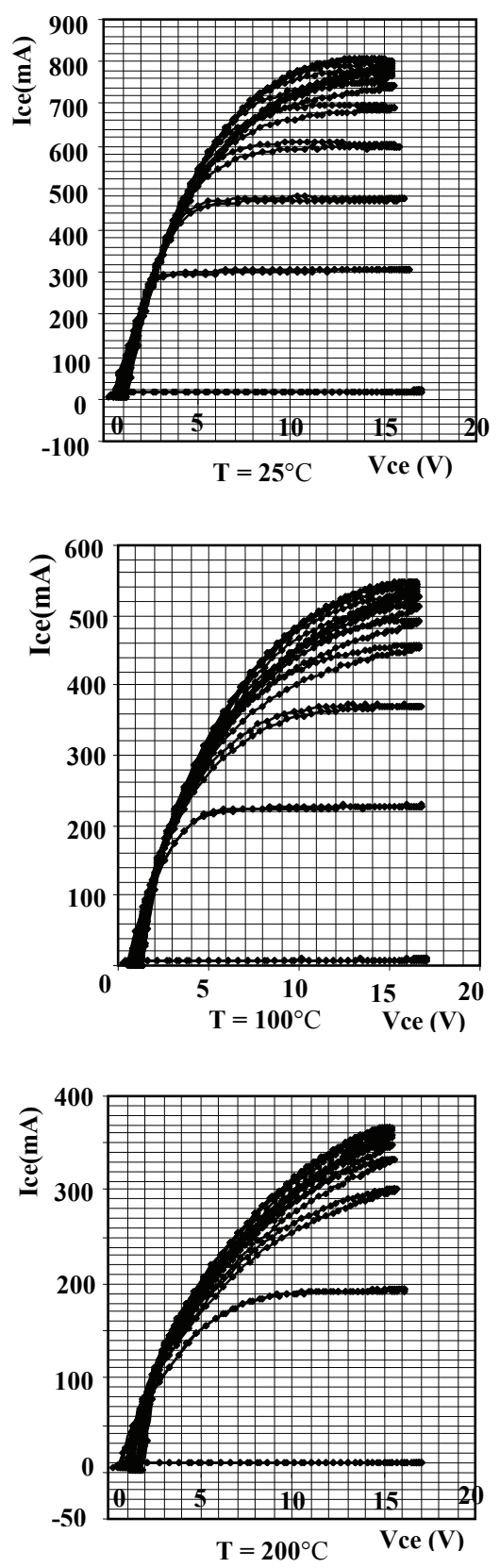

Figure 6. BJT Pair forward Vce-Ic characteristics at $25^{\circ} \mathrm{C}$, $100^{\circ} \mathrm{C}, \& 200^{\circ} \mathrm{C}$.

\subsubsection{Early Voltage}

Table 4 shows representative values of device Early Voltages (VA) at room temperature from three different Reticles. The devices showed $V \mathrm{~A}$ ranging from $115 \mathrm{~V}$ to 2000 V. The $V A$ of a typical Darlington Pair ranges from 115 to $165 \mathrm{~V}$. The VA of Darlington Pairs on some of the Reticles was much higher; ranging from $118 \mathrm{~V}$ to 1900 $\mathrm{V}$. The $V \mathrm{~A}$ of a typical BJT ranges from $325 \mathrm{~V}$ to $347 \mathrm{~V}$. The $V A$ of BJTs on some of the Reticles was much higher; ranging from $267 \mathrm{~V}$ to $2000 \mathrm{~V}$. 

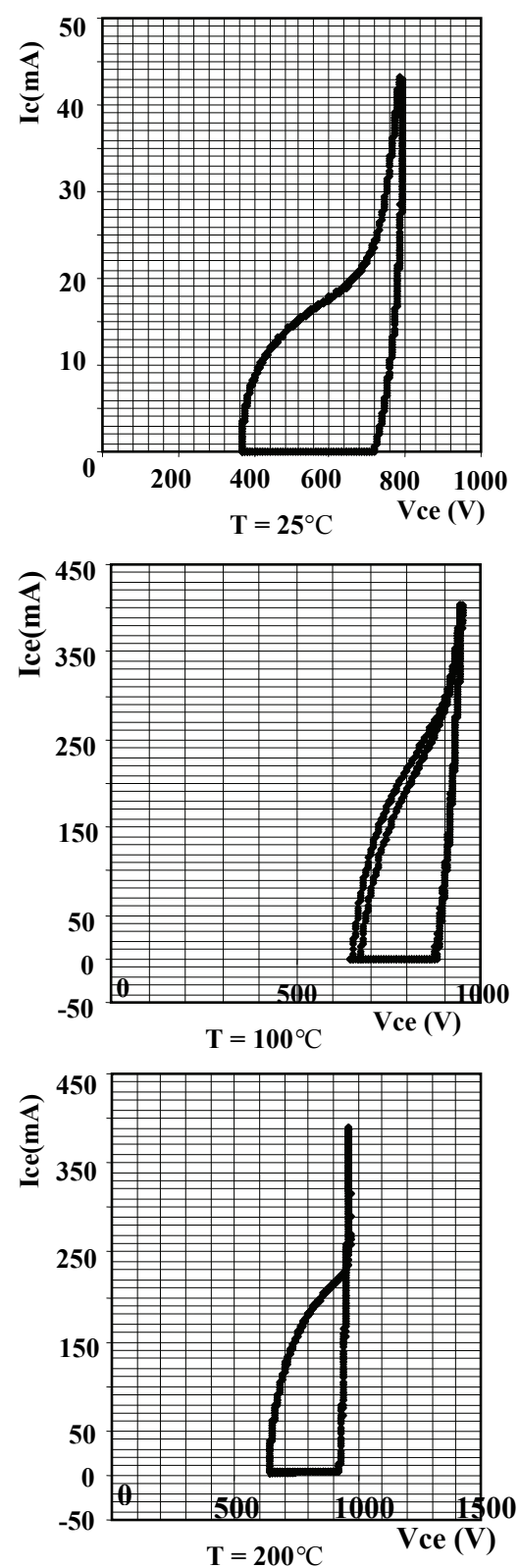

Figure 7. BJT Pair reverse Vce-Ic characteristics at $25^{\circ} \mathrm{C}$, $100^{\circ} \mathrm{C}$ and $200^{\circ} \mathrm{C}$.

Table 4. Early voltage.

\begin{tabular}{ccccc}
\hline Images & & VA1 & VA2 & VA3 \\
\hline Image 1 & Darling & 165.912 & 156.711 & 155.189 \\
Image 3 & Bair & 325.383 & 347.990 & 330.968 \\
\hline
\end{tabular}

The $V$ A values are very high, which could imply that the effective base width is large, possibly due to carrier trapping at deep level defects and compensated base doping. This would be consistent with the low current gains (low base carrier lifetimes) and high Early Voltages observed.

\subsection{Experimental Results - TO-220 BJTs}

\subsubsection{Forward and Reverse (Block) Characteristics, and Current Gain}

The Figures 9 and $\mathbf{1 0}$ show typical forward $(I \mathrm{~b}=20 \mathrm{~mA}$ in steps) and reverse characteristics representative of the $4 \mathrm{H}-\mathrm{SiC}$ BJTs in the TO-220 casing. Figure 11 shows the Ib vs. $\beta$ characteristics for the same devices. Typical values of $\beta$ vary from 5 to 29 , with maximum current gain $(\beta \max )$ of about 30 at room temperature and 200 $\mathrm{mA}$ base current. The decrease in the current gain at room temperature and at $200^{\circ} \mathrm{C}$ is relatively small. The maximum collector current at room temperature was about $6 \mathrm{~A}$ but reduces to about $5 \mathrm{~A}$ at $200^{\circ} \mathrm{C}$. These improved characteristics, compared to the wafer devices, reflect an improved base layer epitaxy process yielding enhanced transport characteristics.

At high temperatures the emitter injection efficiency is reduced, due to the increase in majority carrier concentration in the base from an increased deep acceptor ionization fraction. The expected variation in the forward characteristics between room temperature and at $200^{\circ} \mathrm{C}$ is due to the positive temperature coefficient of $\mathrm{R}_{\mathrm{DS}, \mathrm{ON}}$. The epitaxial growth process was optimized to increase the minority carrier lifetime in the emitter and base layers, which in turn leads to higher dc current gain. This was accomplished by performing the growth at lower

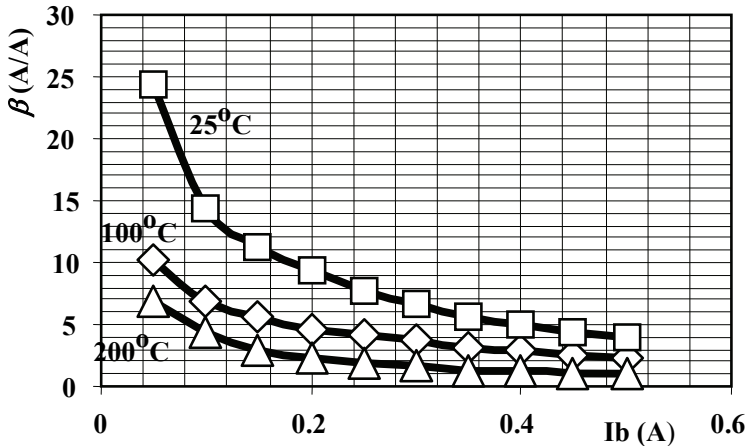

(a)

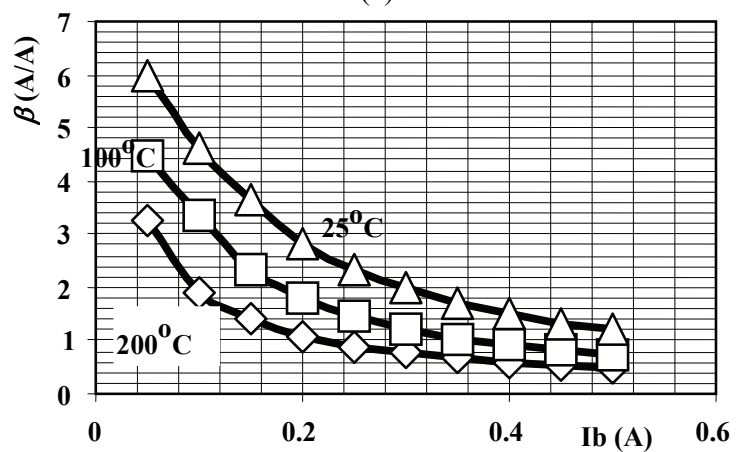

(b)

Figure 8. (a) Darlington Pair Current $\left(I_{b}\right)$ vs. Gain $(\beta)$; (b) BJT Current (Ib) vs. Gain $(\beta)$. 

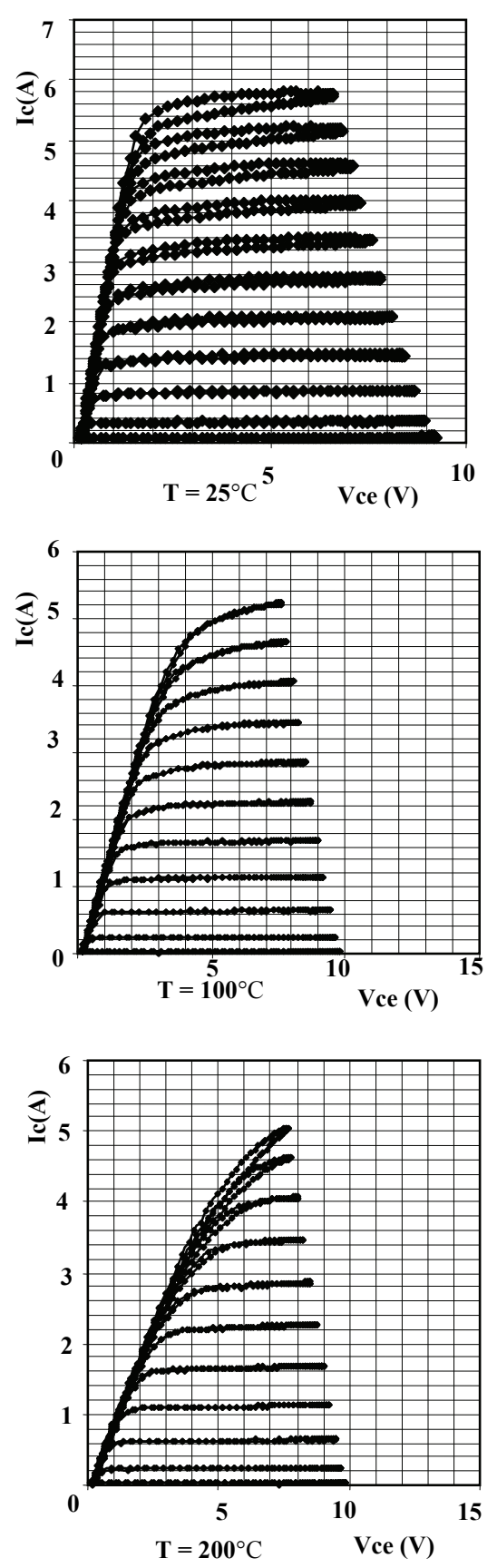

Figure 9. TO-220 BJT forward Vce-Ic characteristics at $25^{\circ} \mathrm{C}, 100^{\circ} \mathrm{C}$ and $200^{\circ} \mathrm{C}$.

temperatures, reducing point defects and impurities, and maintaining stoichiometry of the highly doped emitter layer.

Due to SiC's higher on-state conductivity and lower off-state leakage current at high operating temperatures compared to $\mathrm{Si}$, superior performance at high operating junction temperatures, including lower power dissipation in the active area of the device is realized.

\subsubsection{Dynamic Characteristics}

Figure 12 shows the experimental setup used to study the dynamic characteristics of the $4 \mathrm{H}-\mathrm{SiC}$ BJTs (TO-220 casing) and the sustaining voltage between the collector terminal and the emitter terminal (VCE0(sus)). The dynamic characteristics are performed at room temperature.
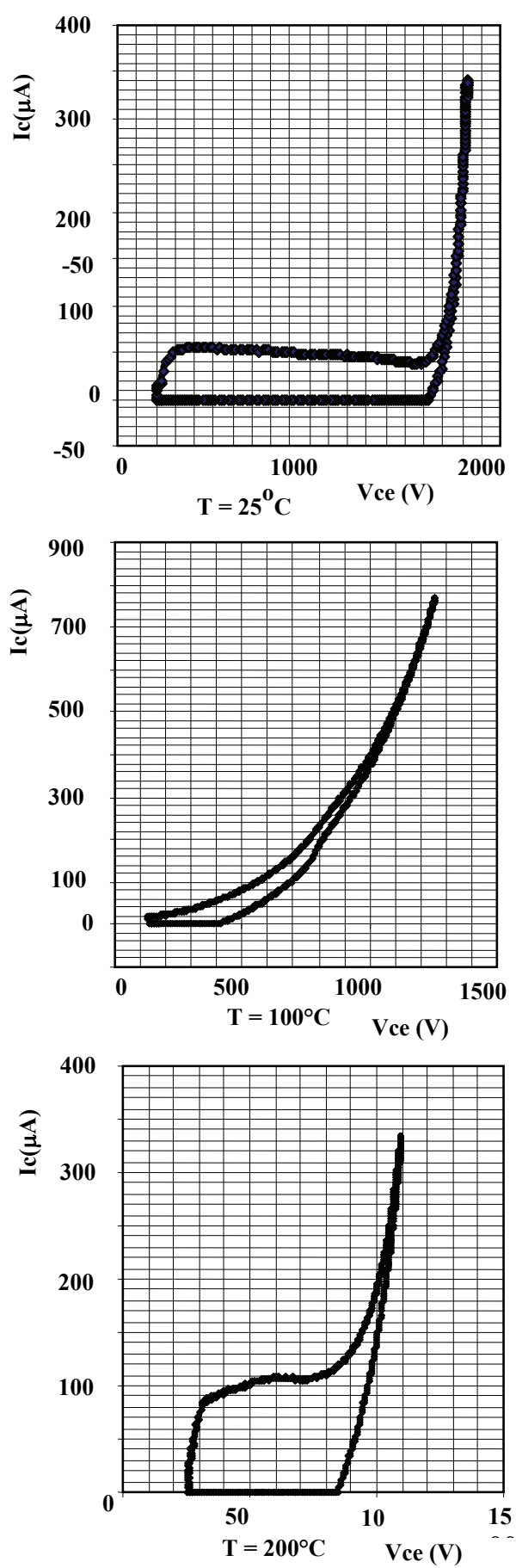

Figure 10. TO-220 BJT reverse $V_{\mathrm{ce}} I_{\mathrm{c}}$ characteristics at $25^{\circ} \mathrm{C}, 100^{\circ} \mathrm{C}$, and $200^{\circ} \mathrm{C}$. 


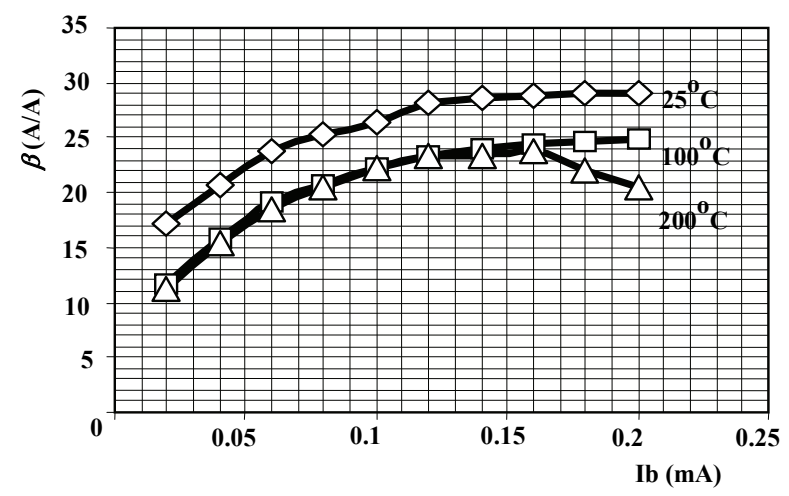

Figure 11. TO-220 BJT Current $\left(I_{b}\right)-\operatorname{Gain}(\beta)$.

The dynamic characteristics analysis was performed at low voltage due to restrictions of the test equipment. The circuit was constructed using a power supply of $15 \mathrm{~V}$, low-power resistors, current probes, and operated from a pulse generator at two switching frequencies $(100 \mathrm{kHz}$ and $1 \mathrm{MHz}$ with a duty-cycle ratio of $50 \%$ ). The load resistance was approximately $20 \mathrm{ohm}$ (rated $20 \mathrm{~W}$ ) connected in the common-emitter configuration mode.

The $\mathrm{SiC}$ power BJT was turned on and off by applying the pulses of the generator to the base of the transistor. The turn-on and turn-off measurements were taken at room temperature.

Figure 13(a) shows typical turn-on characteristics of a $4 \mathrm{H}-\mathrm{SiC}$ BJT with the pulse generator operated at 100 $\mathrm{kHz}$. The turn-on rise time is much faster than a typical Si BJT. A typical turn-on rise time of 312 ns was observed at room temperature. Figure 13(b) shows the turn-off characteristics of the $4 \mathrm{H}-\mathrm{SiC} \mathrm{BJT}$ at room temperature. The turn-off fall time is observed to be nominally $92.5 \mathrm{~ns}$ at room temperature. Turn-on rise time can be improved by decreasing the base contact resistance and by increasing carrier extraction in the base-emitter junction.

Switching speeds in this range are indicative of well controlled minority carrier lifetimes in the base. Very short turn-off times are obtained even though the junction breakdown voltage $V \mathrm{BE}$ is less than $10 \mathrm{~V}$. The dynamic characteristics shows that the switching features of the $\mathrm{SiC}$ power devices can be very fast but at high frequencies the controlling external circuit must have high switching speed (rise time). The very fast switching characteristics show that a SiC-based BJT device has low effective stored charge even when operated at high temperatures. Therefore, the switching losses in $\mathrm{SiC}$ devices caused by the stored charges are negligible in these devices; whereas about $30 \%$ of losses in Si power devices and ICs occur during switching [9]. The switching circuits required can be totally integrated into the switching scheme, and can be dynamically adaptive, fast, ultra low losses, and very small size. The SiC-devices have excel- lent high short circuit capability, especially suitable for commuting applications in power electronics and switching circuits.

Maximum sustaining voltage characteristics, between the collector terminal and the emitter terminal, at a collector current of $100 \mathrm{~mA}$ is shown in Figure 14. A 392 $\mu \mathrm{H}$ inductance was placed in the collector leg of the circuit shown in Figure 12.

The transistor was subjected to a transient voltage forcing the transistor to go into avalanche breakdown for a short time. The sustaining collector-emitter voltage $V \mathrm{CE}$ (sus) was observed to be $40 \mathrm{~V}$ (at collector current of $100 \mathrm{~mA}$ ) at room temperature.

Figure 15(a) shows typical turn-on and turn-off characteristics of a $4 \mathrm{H}-\mathrm{SiC}$ BJT, with the pulse generator operated at $1 \mathrm{MHz}$. It was observed that the voltage at the collector collapsed. Even though the BJT turn-on rise time has been shown to be $312 \mathrm{~ns}(3.205 \mathrm{MHz})$, the power supply failed because the switching speed (the rise time) of the power supply is lower than $1 \mathrm{MHz}$ (restrictions of the test equipment).

Figure 15(b) shows the characteristics of the maximum sustaining collector-emitter voltage at a switching frequency of $1 \mathrm{MHz}$. The sustaining voltage $V \mathrm{CE} 0$ (sus) was observed to be $25 \mathrm{~V}$ (at collector current of $100 \mathrm{~mA}$ ) at room temperature. The sustaining voltage should have remained relatively constant at collector current of 100 $\mathrm{mA}$ for all the switching frequencies. However, the switching speed (the rise time) of the power supply is less than $1 \mathrm{MHz}$ and contributed to this anomaly.

\section{Conclusions}

The experimental data collected confirms some of the

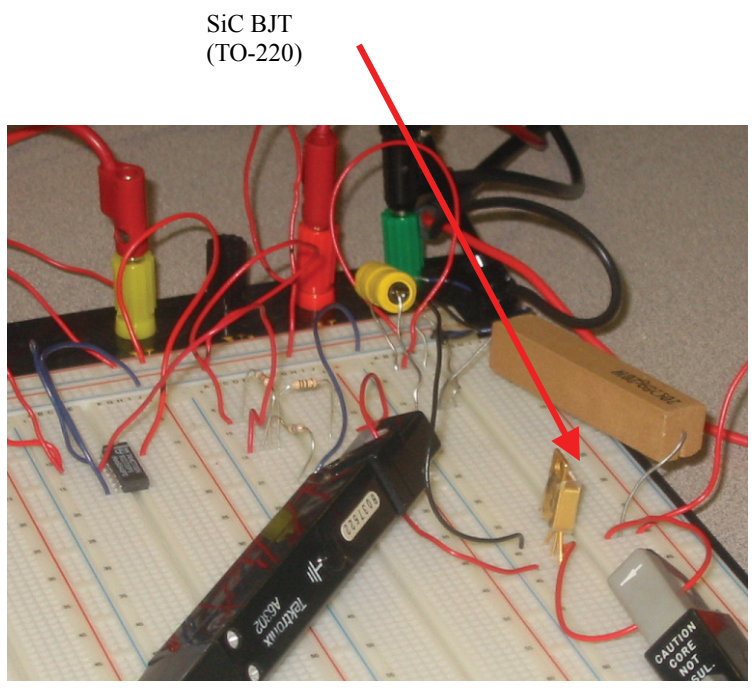

Figure 12. Experimental setup for dynamic characteristics. 


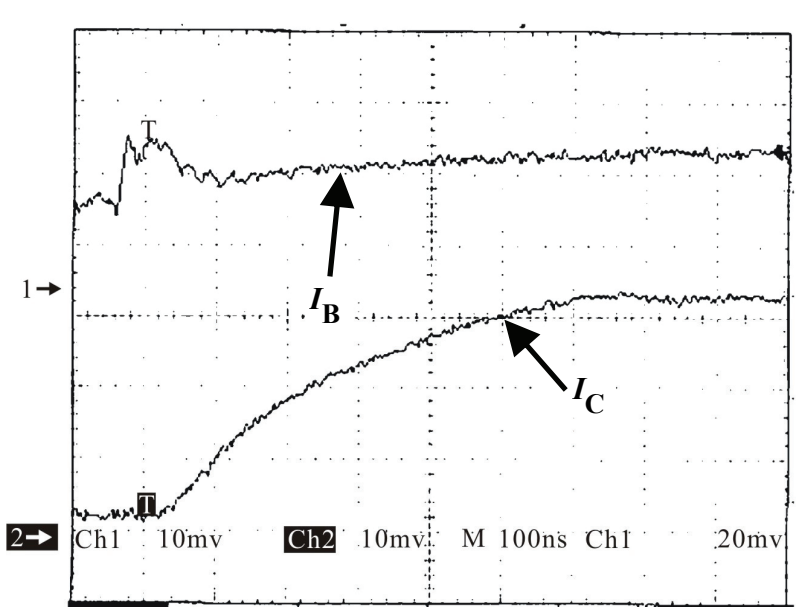

(a)

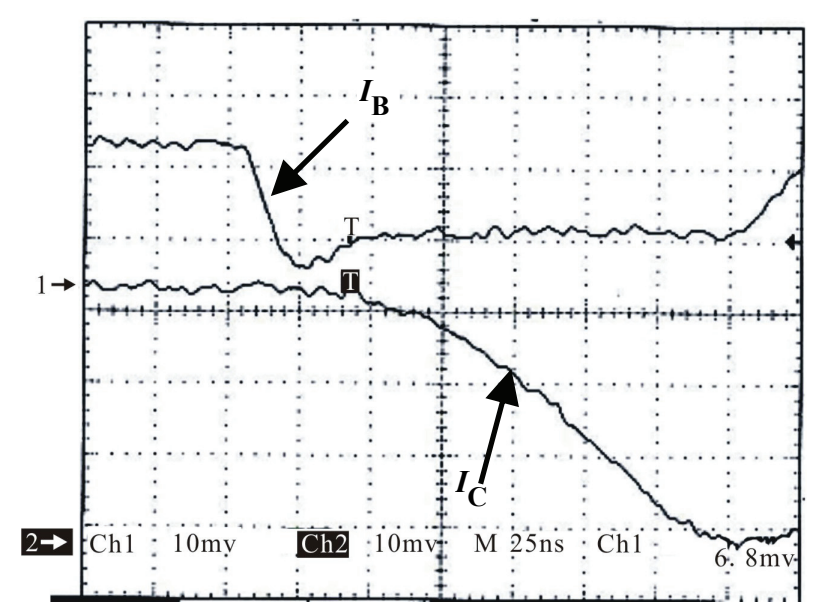

(b)

Figure 13. (a) Turn-on characteristics at 100 kHz; (b) Turnoff characteristics at $100 \mathrm{kHz}$.

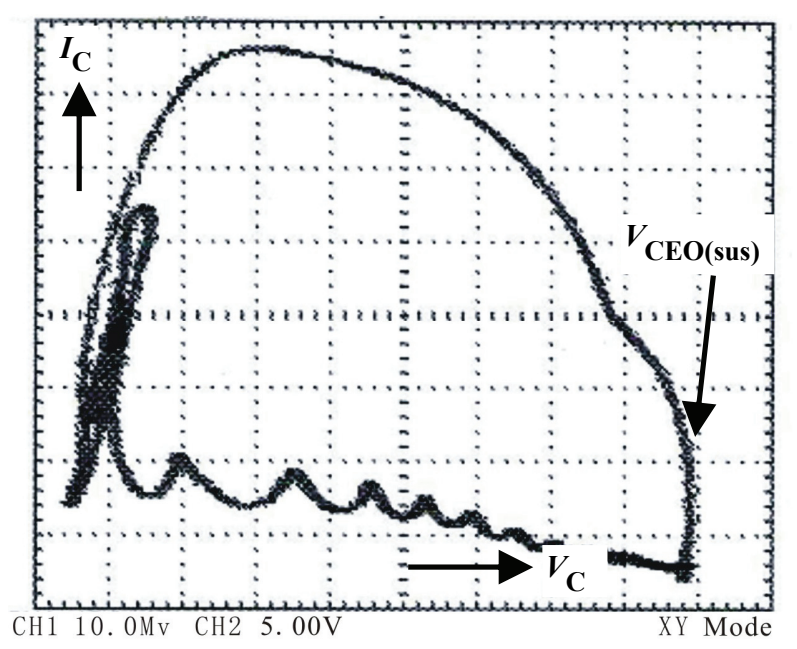

Figure 14. Maximum sustaining voltage (at collector current of $100 \mathrm{~mA}$ ) at $100 \mathrm{kHz}$.
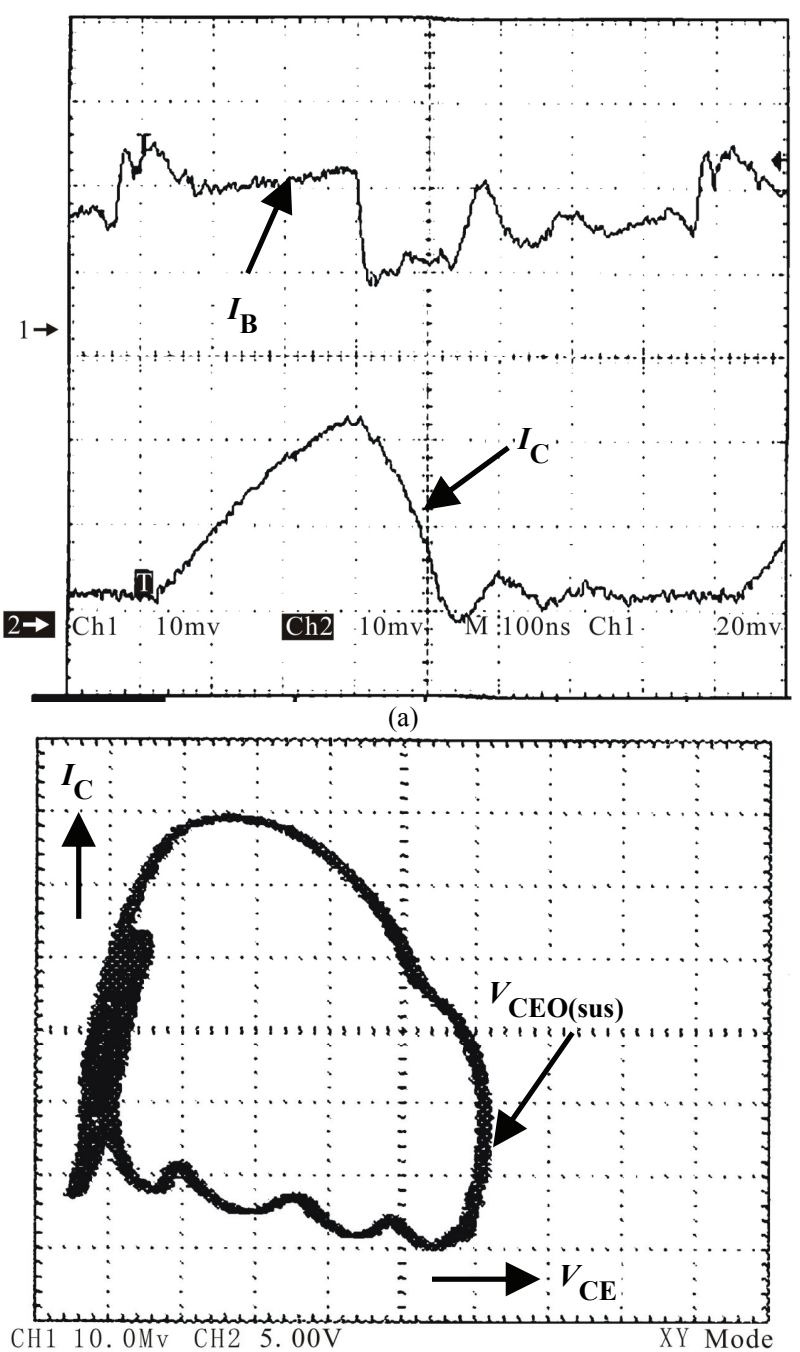

(b)

Figure 15. (a) Dynamic characteristics at $1 \mathrm{MHz}$; (b) Maximum sustaining voltage (at collector current of $100 \mathrm{~mA}$ ) at $1 \mathrm{MHz}$.

superior properties of the $\mathrm{SiC}$ material when used to fabricate electrical and electronics devices for applications in power electronics, instrumentation and measurements. The forward characteristic exhibited stability at high temperatures because of the higher percentage of deep level acceptor ionization in the base region. The gain also decreases as the temperature increases. This negative temperature coefficient property prevents thermal runaway and makes $\mathrm{SiC}$ power BJT devices very attractive for paralleling. The BJTs also show high reverse (blocking) voltages considering the fact that the effective on-resistances $\left(6 \mathrm{~m} \Omega-\mathrm{cm}^{2}\right.$ at $\left.25^{\circ} \mathrm{C}\right)$ of these devices are very small. The current gain, however, was observed to decrease for BJTs with smaller pitches, possibly caused by limited recombination in the base region and low emitter injection efficiency due to emitter crowding ef- 
fects. Base layer ohmic contacts need improvement to reduce the $\sim 5 \mathrm{E}-3 \Omega-\mathrm{cm}^{2}$ specific base contact resistivity measured. The Early Voltage values were very high which likely is due to large effective base widths. This is consistent with low current gain and high Early Voltage effect. The other very prominent features of the SiC BJT include the fast turn-on switching speed, very fast turnoff time, and the robust behavior under critical thermal conditions.

Two key observations can be made from the data collected. First, for example, a 1000-volt $\mathrm{SiC}$ power device will be $5 \mathrm{X}$ smaller or $5 \mathrm{X}$ more efficient than comparable Si device operating at twice the environmental temperature. Secondary, $\mathrm{SiC}$ power devices will reduce switching power losses in many applications.

\section{References}

[1] J. A. Asumadu and J. D. Scofield, "Characteristics of High-Speed Silicon Carbide (SiC) Transistor," Proceedings of the 24th IEEE Instrumentation and Technology Conference, Warsaw, Vol. 2, 1-3 May 2007, p. 36.

[2] A. K. Agarwal, S. H. Ryu, J. Richmond, C. Capell, J. W. Palmour, Y. Tang, S. Balachandran and T. P. Chow, "Large Area, $1.3 \mathrm{kV}, 17 \mathrm{~A}$, Bipolar Junction Transistor in 4H-SiC," ISPSD, 2003.

[3] W. J. Choyke and E. D. Palik, "Silicon Carbide (SiC), Handbook of Optical Constants of Solids," Academic Press, Inc., New York, 1985, pp. 587-595.

[4] H. R. Philip and E. A. Taft, "Intrinsic Optical Absorption of in Single Crystal Silicon Carbide," Silicon Carbide, Eds., J. R. O'Connor and J. Smiltens, New York, Pergamon, 1960, pp. 366-370.

[5] S. Liu and J. D. Scofield, "Thermally Stable Ohmic Con- tacts to $6 \mathrm{H}-$ and $4 \mathrm{H}-\mathrm{p}$-Type $\mathrm{SiC}$," High Temperature Electronics Conference, 1998, HITEC 4th International, San Diego, 14-18 June 1998, pp. 88-92.

[6] M. Bhatnagar and B. J. Baliga, "Comparison of $6 \mathrm{H}-\mathrm{SiC}$, 3C-SiC, and Si for Power Devices," IEEE Transactions on Electron Devices, Vol. 40, No. 4, March 1993, pp. 645 -655 .

[7] C. E. Weitzel, J. W. Palmour, C. H. Carter Jr., K. Moore, K. J. Nordquist, S. Allen, C. Thero and M. Bhatnagar, "Silicon Carbide High-Power Devices," IEEE Transactions on Electron Devices, Vol. 43, No. 10, October 1996, pp. 1732-1741.

[8] W. J. Schaffer, G. H. Negley, K. G. Irvine and J. W. Palmour, "Conductivity Anisotropy in Epitaxial $6 \mathrm{H}$ and $4 \mathrm{H}$ $\mathrm{SiC}$, in Diamond, and Nitride Wide Bandgap Semiconductors," Material Research Society Proceedings, Vol. 339, MRS, Pittsburgh, 1994, pp. 595-600.

[9] S. H. Ryu, A. K. Agarwal, R. Singh and J. W. Palmour, "1800 V NPN Bipolar Junction Transistors in 4H-SiC," IEEE Electron Device Letters, Vol. 22, No. 1, March 2001, pp. 119-120.

[10] P. Fredricks, H. Mitlehner, K. O. Dohnke, D. Peters, R. Schorner, U. Weinert, E. Baudelot and D. Stephani, "SiC Power Devices With Low On-Resistance for Fast Switching Applications," IPSD2000, Toulouse, 22-25 May 2000, pp. 213-216.

[11] A. K. Agarwal, S. H. Ryu, C. Capell, J. Richmond, J. W. Palmour, B. Phan, J. Stambaugh, H. Bartlow and K. Brewer, "SiC BJT's for High Power Switching and RF Applications," Materials Research Society Symposium Proceedings, Vol. 742, 2003, pp. K7.3.1-K7.3.6.

[12] Y. Tang, J. B. Fedison and T. P. Chow, "An ImplantedEmitter 4H-SiC Bipolar Transistor with High Current Gain," IEEE Electron Device Letters, Vol. 22, No. 3, March 2001, pp. 119-120. 